\title{
A comparison of filtration rates among pelagic tunicates using kinematic measurements
}

Kelly R. Sutherland and Laurence P. Madin

K. R. Sutherland, L. P. Madin

Woods Hole Oceanographic Institution, Biology Dept., Woods Hole, MA 02543, USA

e-mail: krakow@whoi.edu phone: 508-289-3206 fax: 508-457-2134

\begin{abstract}
Salps have higher filtration rates than most other holoplankton, and are capable of packaging and exporting primary production from surface waters. A method of kinematic analysis was employed to accurately measure salp feeding rates. The data were then used to explain how diverse body morphologies and swimming motions among species and lifecycle stages influence salp feeding performance. We selected five species, representing a range of morphologies and swimming styles, and used digitized outlines from video frames to measure body-shape change during a pulse cycle. Timevarying body volume was then calculated from the digitized salp outlines to estimate the amount of fluid passing through the filtering mesh. This non-invasive method produced higher feeding rates than other methods and revealed that body volume, pulse frequency and degree of contraction are important factors for determining volume filtered. Each species possessed a unique combination of these three characteristics that resulted in comparable filtration (range: $0.44-15.33 \mathrm{ml} \mathrm{s}^{-1}$ ) and normalized filtration rates (range: $0.21-1.27 \mathrm{~s}^{-1}$ ) across species. The convergence of different species with diverse morphologies on similar normalized filtration suggests a tendency towards a flow optimum.
\end{abstract}

Keywords: Salp, pelagic tunicate, filtration, volume flow rate, locomotion, kinematics, in situ, morphology 


\section{Introduction}

Salps, a type of pelagic tunicate, are common gelatinous holoplankton in oceanic waters that occur mainly in surface waters but sometimes to depths in excess of $1000 \mathrm{~m}$. They swim by jet propulsion, drawing water in through the oral siphon and using muscle bands encircling the cylindrical body to eject water from the atrial siphon (Figure 1a). The resulting pulsed jet propels the animal forward and also creates a feeding and respiratory current. Like other tunicates, salps use a fine mucous mesh to filter a wide range of particles, including bacteria and phytoplankton. During swimming, seawater and associated food particles are constantly being filtered through the mucous filter, which fills much of the body and is continually being generated, and then rolled up as a food strand that is conveyed to the esophagus (Madin 1974). Salps achieve higher rates of filtering and efficiently retain smaller particles $(1 \mu \mathrm{m}-1 \mathrm{~mm})$ than most other planktonic grazers (Madin and Deibel 1998) and therefore play a key part in pelagic ecosystems, particularly when they form dense swarms (Alldredge and Madin 1982). Due to their efficient removal of small particles from surface waters, salps are capable of packaging and exporting primary production to deeper waters, thus influencing biogeochemical cycling (Madin 1982; Madin et al. 2006; Phillips et al. 2009). Some species are vertical migrators, accelerating the transport of fecal material and biomass to deeper water.

Salps have a two part lifecycle composed of asexual, solitary individuals (oozoids) and sexual chains of aggregates (blastozooids). There is considerable variability in the morphology of individuals and the architecture of aggregate forms and this diversity in form is accompanied by variations in swimming behaviors (Madin 1990). Chain architectures can be described by six basic patterns: transverse, cluster, whorl, helical, oblique and linear (Madin 1990). The simplest form, represented by Pegea confoederata in Figure 1b, is the transverse chain. Individual blastozooids are arranged side by side in a double row so that the oral siphons are all in a single plane and the atrial siphons are in a different, parallel plane. The most streamlined architecture, represented by Weelia (Salpa) Cylindrica, is the linear chain (Figure 1d). The blastozooids lie end to end with central axes parallel to the chain axis. 
We hypothesized that each morphology and chain arrangement results in trade-offs between maximizing flux through the filtering meshes and optimizing locomotion.

During a pulse cycle, the buccal aperture closes and circular muscle bands are contracted to eject water out the atrial siphon and propel the animal forward. When the muscles relax and the atrial siphon is closed, the body expands due to the resilience of the tunic, and water is drawn into the oral siphon to fill the body cavity. It is plausible that this mechanism of jet propulsion in salps arose in part as a mechanism for creating filtering flows and not solely for transport. In cnidarian hydromedusae, the wakes generated by swimming motions create distinct feeding currents that directly relate to foraging preferences (Colin and Costello 2002; Colin et al. 2003). Similarly, we wanted to examine whether flows generated by swimming salps vary with morphology and swimming motions and result in differences in feeding performance.

Feeding rates of salps have previously been measured using a variety of methods, including gut pigment measurements, defecation rates and particle depletion rates (reviewed by Madin and Kremer 1995). Each of these methods has advantages and disadvantages but all require at least some aspect of confinement, which leads to an underestimate of filtration rate. Salps are delicate and only survive for short periods of time in the laboratory (Madin 1974). Therefore, it is optimal to make measurements of swimming, feeding, and metabolism in the field. As an alternative method of measuring feeding, several investigators have measured internal body volume and then multiplied by pulse frequency to estimate the volume of seawater passing through the swimming salp (Anderson 1985; Bone et al. 1991; Madin and Kremer 1995). These estimates assume that $100 \%$ of the body volume is expelled during a pulse, and have mostly been used as a basis for comparison to other methods. In squid, however, more sophisticated body outline measurements have been used to estimate volume flow in a jet propelled organism (Anderson and Demont 2000). 
Here we present an in situ method of kinematic analysis to measure change in body volume during a pulse cycle. The resulting volume flow rates are a measure of how much fluid and associated food particles pass through the filtering mesh and provide a metric of the upper limit of filtration. Filtration capability can then be directly compared between species. It is worthwhile to make a distinction between the different units of feeding measurements. Filtration rate, synonymous with volume flow rate, refers to the volume of seawater and associated food particles passing through a feeding filter per unit time. Clearance rate measures a volume of seawater from which particles have been completely removed. If particles are removed with 100\% efficiency, filtration rate and clearance rate are equal.

The work presented here is part of a larger study examining the trade-offs between filtration and jet propulsion among species of pelagic tunicates. The focus of the present study was to accurately measure filtration rates in situ in order to 1) determine an upper limit on salp filtration rate and 2) examine the role of form and function in salp feeding among species and lifecycle stages. Given the important role salps play in cycling of organic material and their potential to remove production from surface waters, accurate field estimates of filtration rates are critical to estimating their ecological impact.

\section{Methods}

\section{Data collection}

Five species of solitary and aggregate salps, Pegea confoederata, Weelia (Salpa) Cylindrica, Cyclosalpa affinis, Cyclosalpa sewelli and, Cyclosalpa polae, were studied in April 2007, January 2008 and January 2009 at the Liquid Jungle Lab on the Pacific coast of Panama (Figure 1). The species selected represent the range of morphologies and swimming styles among salps. In all experiments, a Sony HDR-HC7 high definition camcorder (1440x1080 pixels, 29.97 fps) was used. Bluewater diving techniques were used for observation and collection (Hamner 1975; Haddock and Heine 2005). Divers videotaped salps in situ using an Amphibico Dive Buddy housing and High-Intensity Discharge 10 watt light to illuminate the 
animals and improve contrast. A camera framer with an attached plastic ruler provided scale and helped the videographer keep the study subject in the field of view.

Additional animals were hand-collected in $800 \mathrm{ml}$ plastic jars by divers and videotaped in the laboratory within 6 hours of collection. Salps were transported and maintained in jars at field temperatures $\left(26-28^{\circ} \mathrm{C}\right)$ until the time of filming. Before filming, individuals were gently transferred to an acrylic tank containing seawater from the collection site and allowed to acclimate for several minutes. Tanks were 6-11 L in volume depending on the size of the experimental animal. The tank was side lit to provide contrast and a $1 \mathrm{~cm}$ grid taped to the inside of the tank provided scale.

\section{Determination of kinematics and filtration rate}

Selected video clips when salps were swimming straight, parallel to the camera lens, and in the field of view for one or more pulse cycles were converted from Mini DV into digital files using Vegas Movie Studio editing software (Sony). Salp body length was measured from the oral siphon to the atrial siphon at the beginning and end of each swimming sequence to ensure the body maintained the same distance from the lens during the sequence. At each time step, the outline of the salp was digitized by manually selecting points around the perimeter of the body using MATLAB (MathWorks ${ }^{\mathrm{TM}}$ ). Though manually digitizing the salp outline was time consuming, contrast between the salp and the background was not sufficient to use an automated edge detection method.

Volume was estimated from the two dimensional salp outline using the shell method of integration, where discrete radii spanning from the body central axis to the outer edge of the body are rotated 360 degrees. Volumes of the upper and lower half of the salp were estimated individually and summed to get a more accurate estimate of volume, as presented in Equation 1:

$$
V=0.5 \pi \int_{0}^{L}\left(\left[R_{\text {upper }}(x)\right]^{2}+\left[R_{\text {lower }}(x)\right]^{2}\right) d x
$$


where $L$ is the length of the salp, and $R_{\text {upper }}$ and $R_{\text {lower }}$ are radii at position x along the central axis, $L$. An assumption of this two-dimensional method is that compression is equal in the dorso-ventral and lateral dimensions. The volume at each time step was plotted for each individual swimming salp. A mean pulse frequency, $f_{\text {pulse }}$, for each salp was calculated using Equation 2:

$$
f_{\text {pulse }}=1 / T_{\text {pulse }}
$$

where $T_{\text {pulse }}$ is the mean time interval between two volume maxima (or minima) and represents the time it takes for a single pulse cycle. Volume flow rate, $Q$, was calculated using Equation 3 :

$$
Q=\frac{\bar{V}_{\max }-\bar{V}_{\min }}{\bar{P}_{\text {time }}}
$$

where $\bar{V}_{\max }$ is the mean maximum volume and $\bar{V}_{\min }$ is the mean minimum volume. The degree of compression, $C$, or how much fluid was ejected relative to the maximum volume, was calculated following Equation 4:

$$
C=\frac{\bar{V}_{\max }-\bar{V}_{\min }}{\bar{V}_{\max }}
$$

Normalized volume flow rate, $Q_{n}$, was calculated using Equation 5:

$$
Q_{n}=\frac{Q}{\bar{V}^{b}}
$$

Dividing volume flow rate, $Q$, by the mean body volume, $\bar{V}$, raised to an allometric exponent, $b$, allows for direct comparison between individuals and species of different sizes (Nevill et al. 1992). Note that the average salp volume includes both the internal volume and the body of the salp so these measurements cannot be directly compared to internal salp volumes reported elsewhere in the literature (Andersen 1985; Bone et al. 1991; Madin and Kremer 1995). 
Kinematic volume flow rate data from individuals were combined to examine filtration rate, degree of contraction and pulse frequency among species as a function of body size and to determine how species-specific morphology and kinematics influence filtration rate.

\section{Comparison to other methods}

To evaluate this method relative to other methods, filtration rates of one species from this study, $P$. confoederata, were compared to published clearance rates obtained using gut pigment, defecation rate and particle depletion rate methods. P. confoederata was chosen to do this comparison because this species survives longer in containment than most other salp species and has been the subject of several feeding studies (Harbison and Gilmer 1976; Madin and Cetta 1984; Madin and Kremer 1995).

\section{Results}

Individual body kinematics

Outlines of the body as the salp goes from a maximum to a minimum volume illustrate the extent to which body shape changes, as well as areas where shape change is most concentrated (Figure 2). In all species, contraction of muscle bands was most pronounced towards the anterior and posterior ends but there were individual differences in the percent of the body volume that was expelled. In most individuals, the posterior end appeared most expanded when the salp volume is at a minimum. This is due to the widening of the atrial siphon during fluid expulsion. In most cases, the rest of the body appeared only slightly contracted at a minimum volume but slight differences in the two-dimensional outline correspond with relatively larger differences in volume.

Change in body volume over several pulse cycles are shown for individual salps in Figure 3. An increase in volume corresponds with water entering the oral siphon and a decrease in volume corresponds

with water ejecting from the atrial siphon. Among the solitary salps, the slow-pulsing C. affinis $(0.63 \mathrm{~Hz})$ had the highest percent volume change per pulse (27\%), the fast-pulsing $W$. cylindrica $(2.04 \mathrm{~Hz})$ had a 
more modest change (18\%) and the moderately fast-pulsing $P$. confoederata $(1.72 \mathrm{~Hz})$ had the lowest change in volume (11 \%). Compared to solitary stages of the same genus, the aggregate stage salps examined have higher pulse frequencies and higher percent changes in volume. The slow-pulsing $C$. sewelli $(1.16 \mathrm{~Hz})$ had a high percent volume change per pulse (31 \%), the fast-pulsing W. cylindrica (2.1 $\mathrm{Hz}$ ) had a slightly lower change (28\%) and the moderately fast-pulsing $P$. confoederata $(2.78 \mathrm{~Hz})$ had the lowest volume change (22\%).

\section{Patterns in body kinematics and flow rate}

Kinematic profile data from all individuals $(n=55)$ were combined to examine filtration rate and pulse frequency among species as a function of length and body volume (Table 1). Of the total measurements, 85\% ( $n=47)$ were collected in the field and 15\% $(n=8)$ were collected in tanks. Pulse frequencies decreased with length for all species (Figure 4; Pearson Product Moment Correlation, $r=-0.395, p=$ 0.003) and field and tank pulse frequencies were not significantly different (ANCOVA, length as covariate, $\left.\mathrm{F}_{1,51}=0.26, \mathrm{p}=0.61\right)$. Salps with higher body volumes $(\bar{V})$ had higher filtration rates $(Q)$

(Figure 5; Linear Regression, $\left.\log (\mathrm{Q})=-0.316+0.841 * \log (\bar{V}), \mathrm{r}^{2}=0.85, \mathrm{p}<0.001\right)$. Multiple regression analysis was used to test for the contribution of both pulse frequency $\left(f_{\text {pulse }}\right)$ and body contraction $(C)$ to differences in normalized filtration. The results of the regression indicated that these two variables explained $70 \%$ of the total variation in normalized filtration rate $\left(F_{n}\right)$ (Figure 6; Multiple regression, $\arcsin \mathrm{V}\left(Q_{n}\right)=-0.492+\left(0.299 * f_{\text {pulse }}\right)+(2.259 * \mathrm{C}), \mathrm{r}^{2}=0.70$, ANOVA, $\left.\mathrm{F}_{2,52}=59.50, \mathrm{p}<0.001\right)$. When comparing among species, there were differences in three characteristics between different species and life cycle stages: volume, pulse frequency and degree of body compression (Table 1). A unique combination of these three characteristics within each species resulted in similar filtration rates and normalized filtration rates among all species (Table 1). P. confoederata solitaries filtered the highest volumes and C. sewelli aggregates filtered the lowest volumes, though there were no significant differences among species (Table 1, ANOVA results). W. cylindrica aggregates had higher normalized 
flow rates than all other species but there were no significant differences among species (Table 1, ANOVA results).

Comparison with results from other methods

Feeding rate results for $P$. confoederata from this study were compared to results from previous studies. A comparison of raw data from this study and regression lines from data using three other methods show that this study produced the highest values, setting an upper limit on measured feeding rates (Figure 7; Harbison and Gilmer 1976; Madin and Kremer 1995). Feeding rates from gut pigment studies, a primarily in situ technique, were higher than the lab-based defection rate and particle depletion studies. Data from Madin and Kremer (1995) were reported as clearance rates and data from Harbison and Gilmer (1976), as well as this study are filtration rates. Therefore, comparing directly between results requires an assumption that particles were retained with $100 \%$ efficiency in filtration rate studies.

\section{Discussion}

\section{Morphology, kinematic trade-offs and filtration rates}

Salp species exhibit a range of morphologies and swimming kinematics that play an important role in feeding rates. An examination of the kinematics of swimming at the individual level shows that each species has a unique morphology associated with a particular swimming pattern and manner of changing shape during a pulse (Figures 1, 2, 3). In all species, most of the alteration in shape during a pulse is at the anterior and posterior apertures of the animal due to articulations at the oral and atrial siphons (Figure 2). Body size, pulse frequency and degree of compression are important determinants of the amount of fluid a salp can filter (Figures 5 and 6). Our results suggest that while each species possesses a unique combination of these three characteristics, normalized filtration rates are comparable across species (Table 1). For example, Cyclosalpa species have slow pulse frequencies but compensate with pronounced contraction during pulses that expels a greater volume of fluid compared to the other species studied. Conversely, W. cylindrica solitaries have high pulse frequencies but a shallow pulse that expels 
relatively little fluid. $W$. cylindrica aggregates present a potential exception to this pattern of trade-offs among kinematic traits because they have the highest pulse frequencies and highest pulse compression resulting in a normalized volume filtered that is higher of the other species (Table 1). High pulse frequencies and pulse compression likely contribute to high swimming speeds among $W$. cylindrica and other Salpa species aggregates reported in other studies (Madin 1990; Nishikawa and Terazaki 1994).

Several anatomical features of salps directly impact swimming and pumping capabilities and may help to explain differences in kinematics. The tunic, which surrounds the tube-like body, varies in stiffness and thickness (Hirose et al. 1999). During swimming, the muscle bands contract against the tunic to reduce the body volume and refilling is achieved due to elastic recoil of the tunic (Bone and Trueman 1983). Therefore, the physical properties of the tunic are important for pumping. $P$. confoederata solitaries and aggregates have particularly thick, stiff tunics which probably relates to shallow compressions (Table 1, Fig. 2, Fig.3), due to the difficulty of compressing the test. Similarly, $W$. cylindrica solitaries have relatively stiff tests, though not quite as thick as those of $P$. confoederata, and correspondingly shallow compressions. On the other hand, W. cylindrica aggregates have relatively stiff tests (though slightly thinner than in solitaries) but their compressions are pronounced. As in Salpa fusiformis (Bone and Trueman 1983), lateral regions of the test are thin, possibly allowing for greater articulation at these points. Generally speaking, Cyclosalpa sp. solitaries and aggregates have thin, watery tests that cause these species to become flattened when they are removed from the water. The flexibility of the test allows for deeper compressions with each pulse. Because the tunic provides protection, much like an exoskeleton, having a flimsier body wall may improve pumping capabilities but could also confer increased vulnerability to predation. The number and arrangement of muscle bands as well as the number of muscle fibers, which are frequently used for taxonomic classification (e.g.,Godeaux 1998), might also be expected to influence swimming capabilities but the relationship is less apparent.

\section{Comparison with other methods and broader applications}


The method of using video and kinematic analysis to measure salp feeding compares reasonably to other methods, though it produces consistently higher values (Figure 7). Measured filtration rates of $P$. confoederata solitaries and aggregates from this study were $0.44-15.33 \mathrm{ml} \mathrm{s}^{-1}$. Maximum measured clearance rate using particle depletion methods produced the lowest values, on the order of $1 \mathrm{ml} \mathrm{s}^{-1}$ (Harbison and Gilmer 1976). The maximum measured clearance rate using gut pigment was slightly higher at $\sim 1.7 \mathrm{ml} \mathrm{s}^{-1}$ (Madin and Kremer 1995). Though not shown in Figure 7, P. confoederata filtration rates determined from multiplying pumping rates by internal volume were higher than particle depletion and gut pigment measurements but were lower than measurements from this study (Madin and Kremer 1995). This was surprising because the measurements in Madin and Kremer (1995) were based on the assumption that the total internal volume is expelled, which would tend to overestimate filtration rate, since only a portion of the internal fluid is actually expelled. A closer comparison of the data revealed that the pulse frequencies in the Madin and Kremer study were much lower than those measured in the present study (by half or less), probably because they were tank measurements. The difference in results between the kinematic measurements and the simpler, pumping calculations underscores the importance of making accurate measurements of volume under natural, field conditions whenever possible. Similar to the P. confoederata measurements, W. cylindrica and Cyclosalpa sp. feeding rates measured in this study were also higher than previous measurements obtained using other methods (Table 1; Madin and Deibel 1998). Though a range in feeding rates is probably in part due to differences in environmental parameters and individual behaviors, it is also due to measurement artifact. Of previously used methods, particle depletion involves the longest period of containment and therefore produces the lowest feeding rates. Gut pigment, on the other hand, involves the measurement of chlorophyll and its degradation products from guts of freshly collected salps. Gut pigment results are therefore consistently higher than more laboratory -intensive methods (Figure 7; Madin and Kremer 1995). Kinematic measurements used in this study are less invasive than other methods, easily applied in the field and most accurately reflect natural feeding behaviors. These feeding measurements represent the upper limit of filtration capability among salp species and allow for direct comparisons between salps with different morphologies and 
swimming kinematics. For aggregate forms, kinematic measurements may still occasionally underestimate volume flow rates. Bone and Trueman (1983) found that instantaneous velocities of individuals in an aggregate chain were smoother due to the coordinated swimming of individuals in the chain. Processing of additional fluid due to continuous forward swimming might produce even higher filtration rate than those presented here. A more general limitation of any filtration rate technique is that it indicates how much fluid is processed, but not how many food particles are removed. However, measurements of particle concentration, size spectra and retention rates could be used to extend this method and produce ingestion rates.

This non-invasive technique is particularly useful for active, fast-swimming species or fragile species because when observations are collected in situ, measured filtration rates capture typical feeding behavior. Moreover, certain species, including W. cylindrica, have been deemed "impossible” to maintain in captivity (Madin and Cetta 1984). To varying degrees, most salp species are easily damaged, swim slowly and/or erratically and don’t produce feeding nets consistently when maintained in captivity. When all species were analyzed as a group, there was no significant difference between field and tank measurements in this study (results section). The similarity between field and tank measurements is likely due to careful collection and handling of specimens and very short periods of captivity.

Increasingly, kinematics and fluid mechanics techniques are being using to understand the functional underpinnings of zooplankton feeding. Though feeding rate measurements will relate to the specific study and materials available, the kinematic method sets an upper limit on filtration capability and allows for direct comparisons of feeding rates among salp species, while also revealing particular functional aspects behind feeding efficiency. Similar in situ video analysis techniques could also be adapted to non-invasively examine feeding among other fragile oceanic taxa. For instance, field measurements of appendicularian tail beat frequency and tail dimensions have already been successful in estimating clearance rates that agreed with laboratory studies (Bochdansky and Deibel 1999). In the broader oceanic context, kinematic measurements reaffirm that salps have some of the highest feeding 
rates among filter feeders with rates on the order of 1-10 $\mathrm{ml} \mathrm{s}^{-1}$ (Table 1). Making accurate in situ measurements of salp grazing is critical to furthering our understanding of cycling and removal of primary production in oceanic surface waters.

\section{Optimized filtration}

The finding that salp species with different body shapes have very similar filtration rates can be considered in the context of an optimization theory called constructal theory (Bejan 2000). This broad theory posits that convergences in functional characteristics can be explained by the tendency of systems to evolve in such a way that flow through the system is optimized and energy expenditure is minimized. Therefore there are certain general design goals for optimized flow and configurations that increase performance are predicted. The theory has been applied to a variety of systems including tree shaped flows (Bejan 2005) and locomotion (swimming, flying and running; Bejan and Marden 2006). In the case of salp species, diverse body form and function are tuned to a common normalized volume flow rate (Table 1) which may also minimize energy costs. Given that flow through a salp is central to both filtration and locomotion, optimization of both processes generates the possibility for variation. The comparatively high normalized flow rates of $W$. cylindrica aggregates could be due to other ecological factors. Pumping fulfills a dual role of feeding and swimming, and W. cylindrica and Salpa species are fast swimming and sometimes diel vertical migrators (Madin et al. 1996). It may be that increased energy expenditure for feeding flows is a consequence of faster swimming. Weelia cylindrica has higher weight specific rates of oxygen consumption, carbon ingestion and ammonium excretion compared to most other species of salps (Madin and Deibel 1998). The energetic demands of high pulse frequencies might be balanced by higher rates of filtration and ingestion.

It has been suggested that all salp species are 'ecological equivalents', with little differentiation in diet, distribution, behavior or other parameters of their ecological niches (Yount 1954). The varied morphologies described here and elsewhere (Madin 1990) affect swimming performance and appear 
related to major adaptive strategies (i.e. migrator or not). Our observation that several species with different morphological and kinematic properties end up with similar net flow rates, suggests to us that the differences are important to other biological functions, such as reproduction, predator avoidance or life-history strategy, but that there is some optimum balance of flow rate and energy cost that is most adaptive for the collection of food in the open ocean environment which is home to these species. It would be interesting to make the same observations on the small coastal species Thalia democratica to see if it has similar normalized flow rates.

In many ways, salps appear to be perfectly adapted to life in the limitless space of the open ocean water column. The flow of seawater through their bodies and filtering nets is their central interaction with this environment. Using a series of filtration and energetic calculations, Acuña (2001) previously showed that having a large, watery body allows for a large filtering surface optimized for life in a dilute food environment. Our results suggest optimization of this flow is achieved by different combinations of size, shape and behavior among several different species and generations of salps.

Acknowledgements This work was supported by NSF project OCE-0647723. We thank the people who facilitated work at the Liquid Jungle Lab in Panama, including Ellen Bailey and Luis Camilli, and the SCUBA divers that helped with the project, Emily Abbott, Andrew Gray, David Kushner, Dan Martin, and Dave Sutherland. Erik Anderson was an important resource for data analysis and interpretation. Alex Techet and Tony Moss, as well as an anonymous reviewer, provided useful advice and suggestions. 
Table 1 Morphometric and kinematic data of salp species studied (mean \pm SEM). ANOVA comparisons of volume filtered and normalized volume filtered are presented at bottom of columns. Means labeled with same letters are not significantly different (Tukey's test, $\mathrm{p}<0.05$ )

\begin{tabular}{|c|c|c|c|c|c|c|c|}
\hline & $\mathrm{N}$ & $\begin{array}{l}\text { Length } \\
\text { (mm) }\end{array}$ & $\begin{array}{c}\text { Body } \\
\text { volume } \\
(\mathrm{ml})\end{array}$ & $\begin{array}{c}\text { Pulse rate } \\
(\mathrm{Hz})\end{array}$ & $\begin{array}{c}\% \text { volume } \\
\text { change }\end{array}$ & $\begin{array}{c}\text { Vol. filtered } \\
(\mathrm{ml} / \mathrm{s})\end{array}$ & $\begin{array}{c}\text { Normalized vol. } \\
\text { filtered }\left(\mathrm{s}^{-1}\right)\end{array}$ \\
\hline \multicolumn{8}{|l|}{ Solitary salps } \\
\hline Pegea confoederata & 12 & $47.0 \pm 3.8$ & $15.8 \pm 3.0$ & $1.8 \pm 0.1$ & $17.8 \pm 1.8$ & $5.8 \pm 1.3^{\mathrm{a}}$ & $0.34 \pm 0.03^{\mathrm{a}}$ \\
\hline Weelia cylindrica & 18 & $38.4 \pm 1.3$ & $5.0 \pm 0.4$ & $2.1 \pm 0.1$ & $17.2 \pm 0.9$ & $2.0 \pm 0.2^{\mathrm{ac}}$ & $0.41 \pm 0.03^{\mathrm{a}}$ \\
\hline Cyclosalpa affinis & 4 & $62.5 \pm 6.0$ & $15.9 \pm 3.5$ & $0.67 \pm 0.1$ & $30.3 \pm 1.3$ & $4.2 \pm 1.1^{\mathrm{ac}}$ & $0.24 \pm 0.03^{\mathrm{a}}$ \\
\hline Cyclosalpa sewelli & 4 & $30.5 \pm 6.0$ & $5.2 \pm 3.4$ & $1.4 \pm 0.2$ & $28.9 \pm 2.9$ & $3.6 \pm 3.0^{\mathrm{ac}}$ & $0.47 \pm 0.12^{\mathrm{a}}$ \\
\hline Cyclosalpa polae & 2 & $64.0 \pm 1.0$ & $16.5 \pm 0.3$ & $1.0 \pm 0.6$ & $23.5 \pm 5.5$ & $3.9 \pm 1.8^{\mathrm{ac}}$ & $0.24 \pm 0.11^{\mathrm{a}}$ \\
\hline \multicolumn{8}{|l|}{ Aggregate salps } \\
\hline Pegea confoederata & 8 & $29.3 \pm 3.3$ & $6.9 \pm 2.6$ & $2.1 \pm 0.1$ & $18.3 \pm 1.6$ & $2.5 \pm 0.8^{\mathrm{ac}}$ & $0.43 \pm 0.06^{\mathrm{a}}$ \\
\hline Weelia cylindrica & 2 & $18.5 \pm 2.5$ & $1.0 \pm 0.3$ & $2.5 \pm 0.4$ & $29.9 \pm 1.8$ & $1.0 \pm 0.5^{\mathrm{ac}}$ & $0.86 \pm 0.21^{\mathrm{b}}$ \\
\hline Cyclosalpa sewelli & 5 & $19.0 \pm 1.7$ & $1.6 \pm 0.3$ & $1.6 \pm 0.2$ & $24.6 \pm 2.4$ & $0.6 \pm 0.1^{\mathrm{bc}}$ & $0.44 \pm 0.05^{\mathrm{a}}$ \\
\hline & & & & & & $\begin{array}{l}\mathrm{F}_{7,47}=2.68 \\
\mathrm{p}=0.02\end{array}$ & $\begin{array}{l}\mathrm{F}_{7,47}=4.81 \\
\mathrm{p}<0.001\end{array}$ \\
\hline
\end{tabular}




\section{Figure legends}

Fig. 1 Range of morphologies among solitary (a, c, e) and aggregate (b, d, e) salps from this study. Arrows show direction of water flow. Scale for all drawings at lower right

Fig. 2 Representative salp outlines from digitized video frames indicating body shape and size as volume decreases from a maximum to a minimum. Anterior end of salp is to the right side of plot

Fig. 3 Body volumes of individual solitary (a-c) and aggregate (d-f) salps. Aggregate volumes are from one individual in chain

Fig. 4 Relationship between salp body length and frequencies. Tank measurements are circled to distinguish them from field measurements

Fig. 5 Relationship between salp body volume and filtration rate

Fig. 6 Influence of a) salp pulse frequency and b) percent contraction on filtration normalized to body volume raised to allometric exponent

Fig. 7 Comparison of $P$. confoederata clearance rate methods from this study (open symbols) with other studies (regression lines). Regression lines are extended (thin lines) to facilitate visual comparisons. Gut pigment and defecation rate data from Madin and Kremer (1995). Particle depletion data from Harbison and Gilmer (1976) 
A. Pegea confoederata solitary

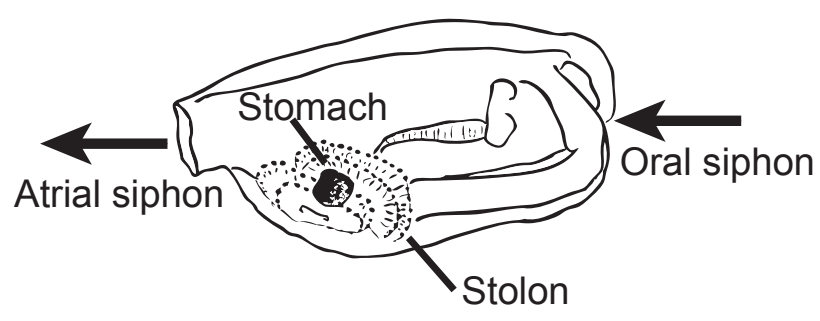

B. Pegea confoederata aggregate

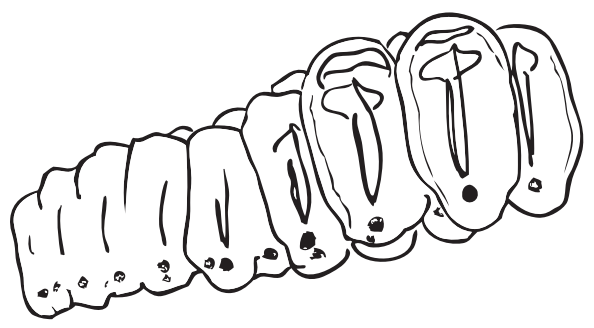

C. Weelia (Salpa) cylindrica solitary

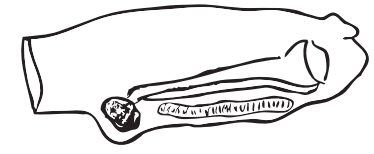

E. Cyclosalpa affinis solitary

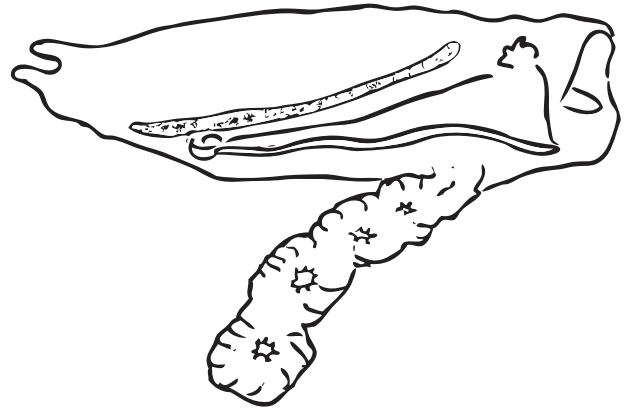

D. Weelia (Salpa) cylindrica aggregate

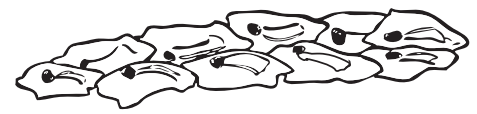

F. Cyclosalpa sewelli aggregate

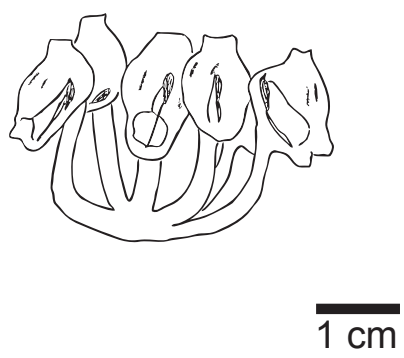

Fig. 1 Range of morphologies among solitary (a, c, e) and aggregate (b, d, e) salps from this study. Arrows show direction of water flow. Scale for all drawings at lower right 

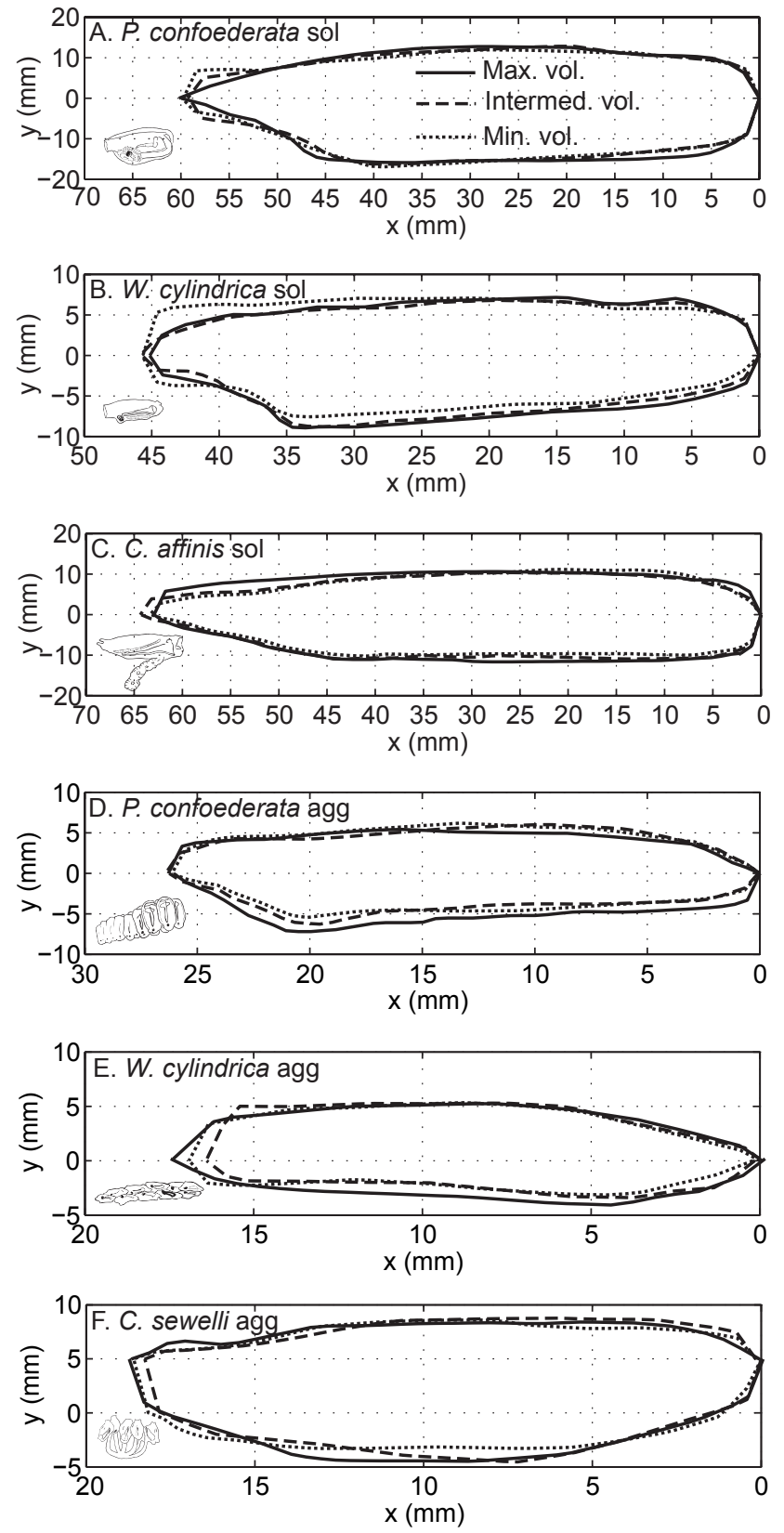

Fig. 2 Representative salp outlines from digitized video frames indicating body shape and size as volume decreases from a maximum to a minimum 

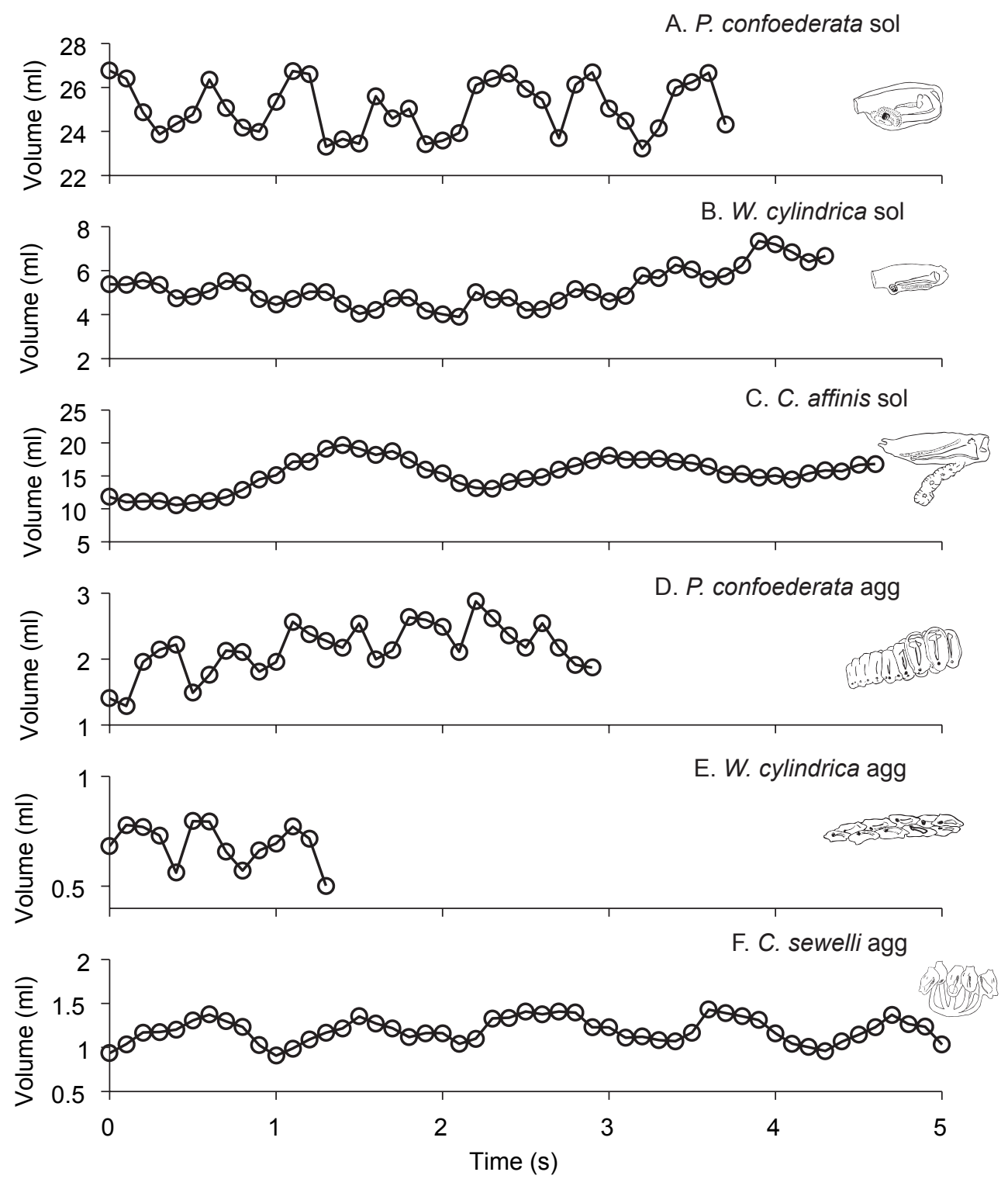

Fig. 3 Body volumes of individual solitary (a-c) and aggregate (d-f) salps. Aggregate volumes are from one individual in chain 


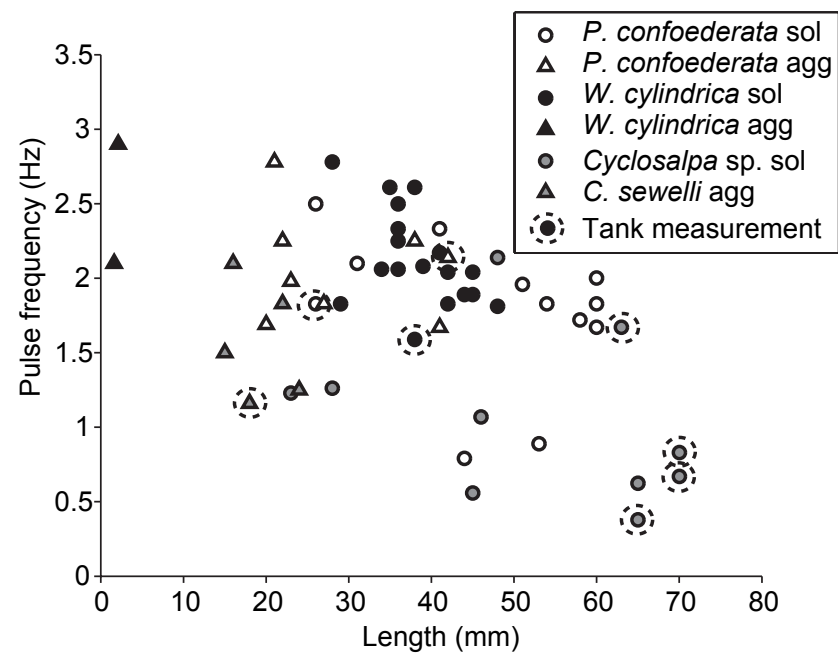

Fig. 4 Relationship between salp body length and pulse rate. Tank measurements are circled to distinguish them from field measurements 


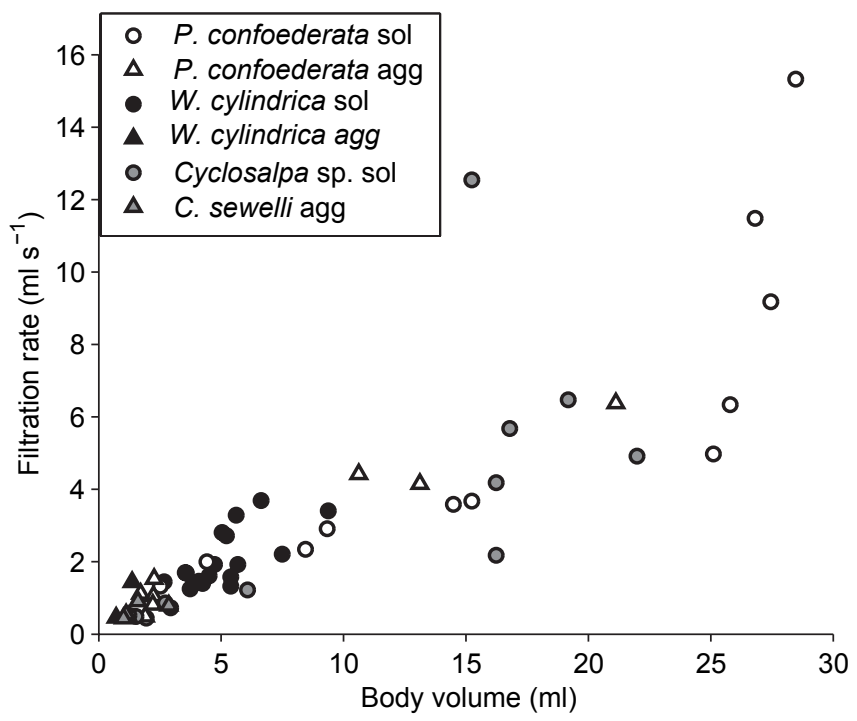

Fig. 5 Relationship between salp body volume and filtration rate 

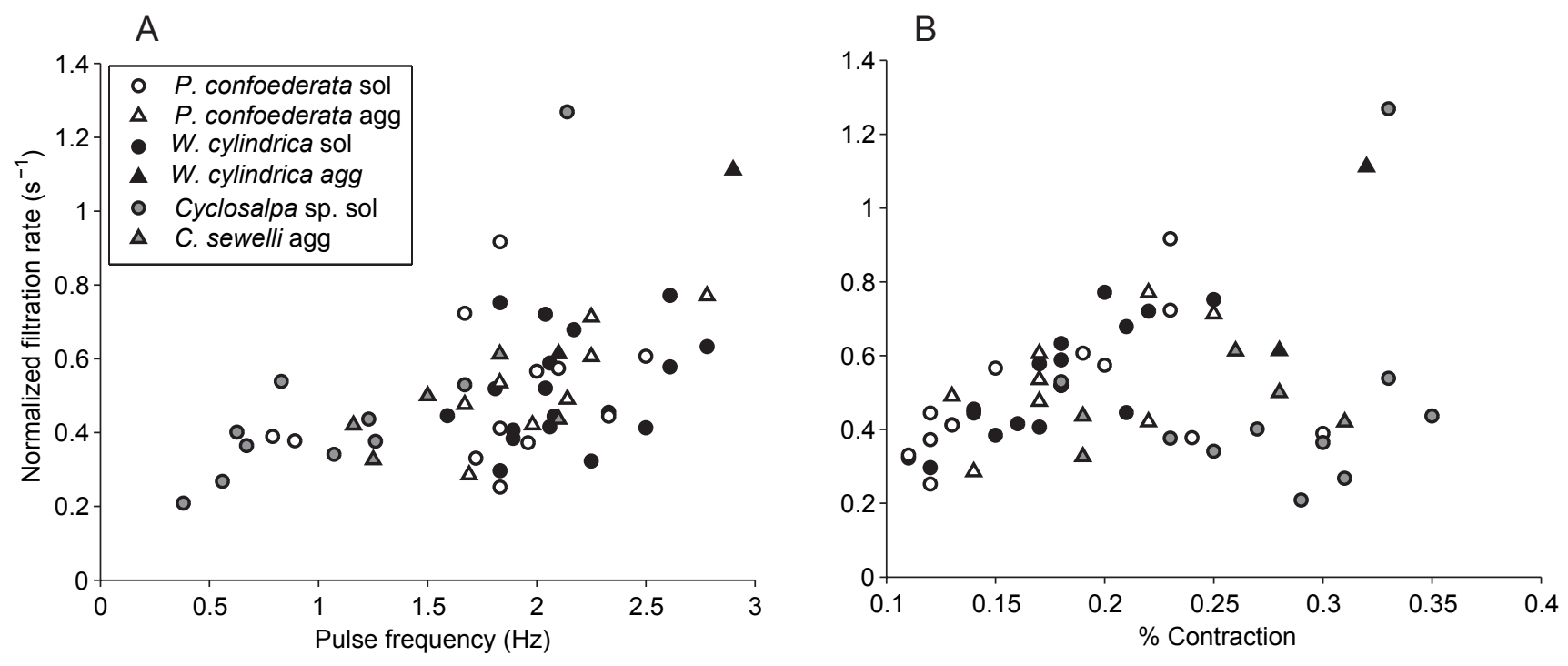

Fig. 6 Influence of a) salp pulse rate and b) percent contraction on filtration normalized to body volume 


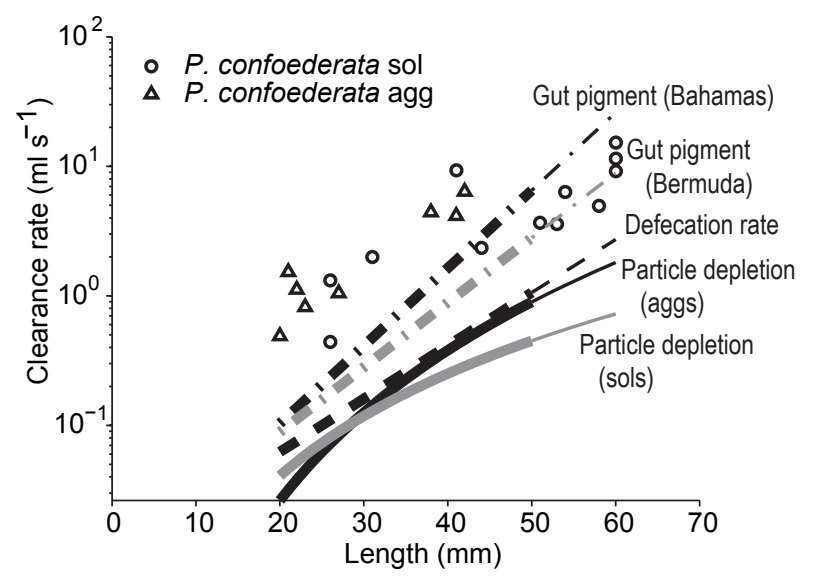

Fig. 7 Comparison of P. confoederata clearance rates methods from this study (open symbols) with other studies (regression lines). Regression lines are extended (thin lines) to facilitate visual comparisons. Gut pigment and defecation rate data from Madin and Kremer (1995). Particle depletion data from Harbison and Gilmer (1976) 


\section{References}

Acuna JL (2001) Pelagic tunicates: Why gelatinous? American Naturalist 158: 100-107

Alldredge AL, Madin LP (1982) Pelagic tunicates: unique herbivores in the marine plankton. BioScience 32: 655-663

Andersen V (1985) Filtration and ingestion rates of Salpa fusiformis Cuvier (Tunicata: Thaliacea): Effects of size, individual weight and algal concentration. J Exp Mar Biol Ecol 87: 14-29

Anderson EJ, Demont ME (2000) The mechanics of locomotion in the squid Loligo pealei: Locomotory function and unsteady hydrodynamics of the jet and intramantle pressure. J Exp Biol 203: 28512863

Bejan, A (2006) The constructal law of organization in nature: tree-shaped flows and body size. . J Exp Biol 208: 1677- 1686

Bejan A (2000) Shape and structure, from engineering to nature. Cambridge, UK: Cambridge University Press

Bejan A, Marden JH (2006) Constructing animal locomotion from new thermodynamics theory. Am Sci 94: 342-349

Bochdansky AB, Deibel D (1999) Measurement of in situ clearance rates of Oikopleura vanhoeffeni (Appendicularia : Tunicata) from tail beat frequency, time spent feeding and individual body size. Mar Biol 133: 37-44

Bone Q, Braconnot JC, Ryan KP (1991) On the pharyngeal feeding filter of the salp Pegea confoederata (Tunicata, Thaliacea). Acta Zool 72: 55-60

Bone Q, Trueman ER (1983) Jet propulsion in salps (Tunicata: Thaliacea). J Zool Lond 201: 481-506

Colin SP, Costello JH (2002) Morphology, swimming performance and propulsive mode of six cooccuring hydromedusae. J Exp Biol 205: 427-437

Colin SP, Costello JH, Klos E (2003) In situ swimming and feeding behavior of eight co-occuring hydromedusae. Mar Ecol Prog Ser 253: 305-309

Godeaux J (1998) The relationship and systematics of the Thaliacea, with keys for identification. In: Bone Q (ed) The biology of pelagic tunicates. Oxford University Press, New York, pp 273-294

Haddock SHD, Heine JN (2005) Scientific blue-water diving. California Sea Grant College Program Report No. T-057

Hamner WM (1975) Underwater observations of blue-water plankton: Logistics, techniques, and safety procedures for divers at sea. Limnol Oceanogr 20: 1045-1051

Harbison GR, Gilmer RW (1976) The feeding rates of the pelagic tunicate Pegea confederata and two other salps. Limnol Oceanogr 21: 517-528 
Hirose E, Kimura S, Itoh T, Nishikawa J (1999) Tunic morphology and cellulosic components of pyrosomas, doliolids, and salps (Thaliacea, Urochordata). Biol Bull 196: 113-120

Madin LP (1974) Field observations on the feeding behavior of salps (Tunicata: Thaliacea). Mar Biol 25: 143-147

Madin LP (1982) Production, composition and sedimentation of salp fecal pellets in oceanic waters. Mar Biol 67: 39-45

Madin LP (1990) Aspects of jet propulsion in salps. Can J Zool 68: 765-777

Madin LP, Cetta CM (1984) The use of gut fluorescence to estimate grazing by oceanic salps. J Plankton Res 6: 475-492

Madin LP, Deibel D (1998) Feeding and energetics of Thaliacea. In: Bone Q (ed) The biology of pelagic tunicates. Oxford University Press, New York, pp 81-103

Madin LP, Kremer P (1995) Determination of the filter-feeding rates of salps (Tunicata, Thaliacea). ICES J Mar Sci 52: 583-595

Madin LP, Kremer P, Hacker S (1996) Distribution and vertical migration of salps (Tunicata, Thaliacea) near Bermuda. J Plankton Res 18: 747-755

Madin LP, Kremer P, Wiebe PH, Purcell JE, Horgan EH, Nemanzie DA (2006) Periodic swarms of the salp Salpa aspera in the Slope Water off the NE United States: Biovolume, vertical migration, grazing and vertical flux. Deep Sea Res I

Nevill AM, Ramsbottom R, Williams C (1992) Scaling physiological measurements for individuals of different body size. Eur J Appl Physiol 65: 110-117

Nishikawa J, Terazaki M (1995) Measurement of swimming speeds and pulse rate of salps using a video equipment. Bull Plankton Soc Japan 41: 170-173

Phillips B, Kremer P, Madin LP (2009) Defecation by Salpa thompsoni and its contribution to vertical flux in the Southern Ocean. Mar Biol 156: 455-467

Yount JL (1954) The taxonomy of the Salpidae (Tunicata) of the Central Pacific Ocean. Pac Sci 3: 276330 